\title{
Analysis of displacements in beam structures and shells with middle developable surfaces
}

\author{
Marina Rynkovskaya \\ RUDN University, Engineering Department, 6 Miklukho-Maklaya st., Moscow, Russia, 117198
}

\begin{abstract}
Generally the displacements of the beams are calculated by the traditional methods of structural mechanics with the help of approximate formulas which provide good results for linear tasks. The author shows that the approximate formula is not suitable for analysis in the case of geometrical nonlinearity which occurs during the manufacturing process of bending developable shells. The comparison of results got by methods of structural mechanics and shell theory for the shells with developable middle surfaces is given.
\end{abstract}

\section{Introduction}

The displacements of the beams are traditionally calculated by approximate equations of the methods of the structural mechanics, while the displacements of flexible structures are mostly based on mathematical models with the systems of nonlinear differential equations [1-4]. Professor Krivoshapko S.N. [5] suggested an exact method of the determination of internal bending moments which occur during the process of parabolic bending of thin developable shells with the help of differential geometry methods, Hooke's law and Love's formulas for the elastic shell theory. In a paper [6], the shell stress-strain state in view of very large displacements and very slight normal and shear strains is studied.

In a paper [7], Elenitsky E.Ya. suggested the algorithm of static calculation of geometrically nonlinear compound thin structures with the help of linear differential equations of moment theory and considered the nonlinearity by assigning unknown initial angular displacement of each segment retaining the form of the generating line. Unknown values of algebraic equations resolving system are the arbitrary constants of the general solution and the initial angles of generating lines rotation, while linearization is realized by Newton-Raphson iterative method. It is shown in the paper on examples of the console beam and the hinged annulus that such approach provides the high precision of results.

\section{Methods applied to the beam}

\subsection{Approximate method applied to the beam}

It is well known that displacements in the beam in traditional linear theory of structural mechanics [8] can be found by the formula of the advanced mathematics

$$
\frac{y^{\prime \prime}}{\left(1+y^{\prime 2}\right)^{3 / 2}}=k=\frac{1}{R},
$$

where $\mathrm{k}$ is a curvature of the curve; $\mathrm{R}$ is a radius of the curve; $y=y(x)$ is a deflection equation; $y^{\prime}$ is a tangent of the angle of inclination of the tangent to the elastic line of a beam axis.

In practice, these angels are very small and one can neglect their squares in comparison with the unit that allows getting the famous equation named the main differential equation of the curved axis of a beam:

$$
y^{\prime \prime}=\frac{M}{E I},
$$

(where $\mathrm{E}$ is a modulus of elasticity; I is a moment of inertia, $\mathrm{M}$ is an inner bending moment), which is approximate, because the equation of the axis curvature is replaced by an approximate one, and deformations caused by shear forces are also not considered. In most cases, this influence is insignificant and can be neglected. However, let us describe the equation without any approximations and analyse the accurate results.

\subsection{Precise method applied to the beam}

To simplify the calculations, we will consider the load to be consistent and consist only of the converging bending moment attached at the end of a console beam (Fig. 1). In this case, the Eq. 1 will be

$$
\frac{E I y^{\prime \prime}}{\left(1+y^{\prime 2}\right)^{3 / 2}}=M,
$$

where $M=$ const is an inner bending moment.

On integrating the Eq. 3, one can obtain the following equation of the deflection of an axis: 


$$
y=\frac{1}{M} \sqrt{(E I)^{2}-(M x)^{2}-\frac{E I}{M}},
$$

which is an equation of a circle, while the approximate method (Eq. 2) gives us the deflection equation in the form of parabola:

$$
y=\frac{M x^{2}}{2 E I} .
$$

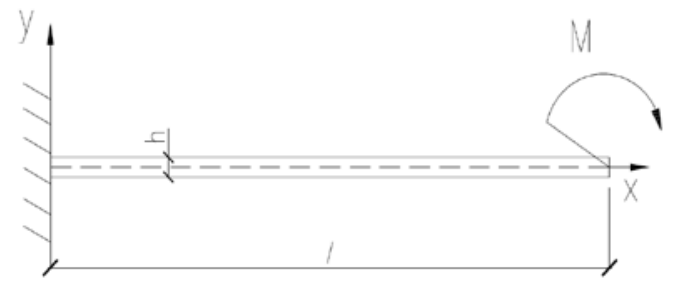

Figure 1. The analyzed console beam

Test. Let us analyze an example calculated by the means of two approaches (approximate and precise). The steel beam with the following geometrical and physical characteristics: section height is $\mathrm{h}=0.01 \mathrm{~m}$; section width is $\mathrm{b}=1 \mathrm{~m}$; the length is $1=6 \mathrm{~m}$; Young's modulus is $E=2.06 \cdot 10^{5} \mathrm{MPa}$, the yield point stress is $\sigma_{y}=245 \mathrm{MPa}$

; was calculated. The displacements are shown on Fig. 2 and in the Table 1, where $y(x)$ was calculated by precise method (Eq. 4) and yl(x) was calculated by approximate method (Eq. 5).

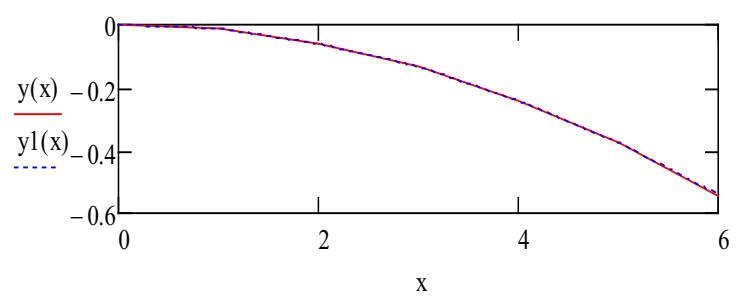

Figure 2. Displacements $y(x)$ and $y l(x)$ which are calculated by precise (Eq. 4) and approximate (Eq. 5) methods respectively.

Table 1. Displacements $y(x)$ and $y l(x)$ which are calculated by precise (Eq. 4) and approximate (Eq. 5) methods respectively and the difference $\delta$ in the results

\begin{tabular}{|c|c|c|}
\hline$(x)=$ & $1(x)=$ & $\delta(\mathrm{x})=$ \\
\hline 0.000000 & 0.000000 & $3.385 \cdot 10^{-5}$ \\
\hline-0.015003 & -0.015000 & 0.023 \\
\hline-0.060054 & -0.060000 & 0.09 \\
\hline-0.135274 & -0.135000 & 0.203 \\
\hline-0.240870 & -0.240000 & 0.363 \\
\hline-0.377133 & -0.375000 & 0.569 \\
\hline-0.544446 & -0.540000 & \\
\hline
\end{tabular}
of displacements $y(x)$ and $y l(x)$.
The results of displacements on Fig. 2 are shown in meters. The displacements are more than 50 thicknesses of the beam, so the task is geometrically nonlinear and cannot be analyzed by linear theory.

The differences in results of displacements which are calculated by approximate and precise methods

$$
\delta(x)=\frac{y(x)-y 1(x)}{y 1(x)} \cdot 100
$$

are shown in Table 1. The biggest difference on the edge of the beam is 0.569 per cent that can be considered as a small difference, but in the case of bigger displacements such as 100 thicknesses the difference is considerable which will be shown further.

\section{A precise method applied to the developable shells}

According to [9], a developable surface can be flattened onto a plane without stretching, tearing or creasing, and tangent lines of the edge of regression (cuspidal edge) of this surface generate it. Since this type of surfaces is widely used in manufacturing [10-15] in many fields such as shipbuilding $[16,17]$, engineering [18] and architecture $[19,20]$ and products are mostly obtained by the means of bending, the problem of plastic deformations should be taken into account. However, most works about developable surfaces do not concern to this point [21-27].

In the case of manufacturing of developable surfaces by applying the bending moment My to the plane plate, one can be interested in obtaining the minimum radius Rmin of the bending until which the plate works in elastic stage. The plastic moment My, created by the normal stresses, occurs when maximum normal stresses mount to the yield point stresses $\left(\sigma_{s, \max }=\sigma_{y}\right)$ is

$$
M_{\mathrm{y}}=\frac{\sigma_{y} h^{2}}{6} \text {. }
$$

After rewriting the Eq. 4 into more traditional form for the circle

$$
y=\sqrt{\frac{(E I)^{2}}{M^{2}}-x^{2}-\frac{E I}{M}},
$$

one can obtain the evaluation of the radius of the deformation axis of the beam

$$
R=\frac{E I}{M}=\text { const }
$$

The Eq. 6 can be called a radius of a curve of the developable surfaces while bending.

On the other hand, it was shown by the author in [28] that the minimum radius of the developable surface while manufacturing can be also calculated by another approach with the help of the shell theory

$$
R_{\min }=\frac{E I}{M_{y}} \frac{1}{\left(1-v^{2}\right)} .
$$


According to the Eq. 6 and Eq. 7 the difference between standard methods of resistance of materials and the method of the shell theory leads to different results. Thus, in the case when Poison's ratio is $v=0.3$, the minimum radius occurs to be almost 10 per cent higher than the radius which is calculated by standard methods of structural mechanics.

\section{Practical applications}

Let us take the steel rectangular plate with the following geometrical and physical characteristics: section height is $\mathrm{h}=0.01 \mathrm{~m}$; section width is $\mathrm{b}=1 \mathrm{~m}$; the length is $1=6 \mathrm{~m}$; Poison's ratio is $v=0.3$; Young's modulus is $E=2.06 \cdot 10^{5} \mathrm{MPa}$, the yield point stress is $\sigma_{y}=245 \mathrm{MPa}$

. Let it be required to produce a product in the shape of a half circle (C-shaped plate) with the radius $\mathrm{R}=5 \mathrm{~m}$ (Figure 3 ) by bending.

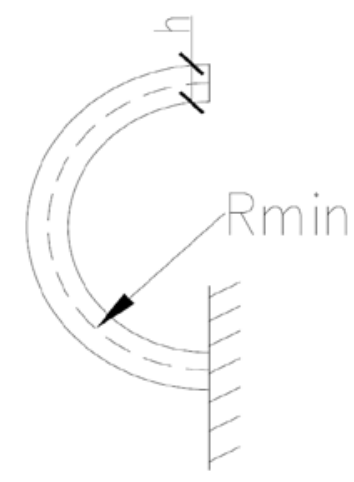

Figure 3. The required C-shaped product

We calculate the minimum value of the radius ( $\left.R_{\min }\right)$ of bending at which the plastic deformations will not occur (the shaped plate will turn around into a plane plate again). In other words, the plate is bent without plastic

deformations ( $\sigma_{s, \max } \leq \sigma_{y}$ ).

The plastic bending moment My, created by the normal stresses, occurs when maximum normal stresses mount to the yield point stresses $\left(\sigma_{s, \max }=\sigma_{y}\right.$ ), is

$$
M_{\mathrm{y}}=\frac{\sigma_{y} h^{2}}{6}=4038 \mathrm{~N} \cdot \mathrm{m} / \mathrm{m} \text {. }
$$

According to Eq. 6 and Eq. 7, the minimum value of the radius of bending without plastic deformations will respectively be $\mathrm{Rmin}=4.082 \mathrm{~m}$ for the method of resistance of materials and $\mathrm{Rmin}=4.485 \mathrm{~m}$ for the shell theory method. This means that required product cannot be manufactured by simple bending because after removing the clamps product will turn back into the plane plate.

\section{Results and discussion}

In the case when the biggest displacement $y(x)$ is less or the same as the thickness $h$ of the beam, the difference between displacements which are calculated by accurate and approximate methods is very small (less than 0.0002 per cent) which coincides with linear theory. In the case when the biggest displacement $\mathrm{y}(\mathrm{x})$ is less than 50 thicknesses, the difference is also small and shown on Fig. $3(\delta \max =0.569$ per cent $)$.

However, in the case of developable shells which are manufactured by bending the displacements are much bigger and the difference in results can be considerable. For example, in the case when the biggest displacement $\mathrm{y}(\mathrm{x})$ is more than 100 thicknesses the difference is 2.36 per cent, while in the case of displacements more than 200 thicknesses the mistake may achieve even 10 per cent.

Obviously, the suggested analysis is not absolutely accurate as far as it does not take into account the displacements along the coordinate $\mathrm{x}$, but it generally shows that once displacements are very big, for example, in the case of manufacturing a product from the thin plate by bending, the traditional approximate equations cannot be used. In addition, the suggested equations can be improved by further research and the displacements along the line $\mathrm{x}$ can be also be included in analysis.

For future researchers, it can be interesting to conduct an experiment that will confirm the suggested theoretical results, the minimum value of the bending radius. There have not been found any information in this field of research, except [7] where some approaches for calculation of this experimental task are presented.

Generally, most engineers consider the task of bending of the thin plate to the task of bending of the middle surface, and do not take into account the normal strains, because as it is well known normal strains do not occur on the middle surface. In practice, since the margin of safety is usually very high for such products as steel tubes, such approach does not lead to any problems. However, it can be useful to consider plastic deformations when plate is being bent into the product.

\section{Conclusion}

The investigation presented shows some problems in usage of linear and geometrically nonlinear theories for beams and shell structures with developable middle surface. There are some results of analysis of the console beam which was calculated by both the approximate and precise methods of structural mechanics as well as by the shell theory. Since the plastic deformations can occur during the manufacturing process of bending, the determination of these deformations in the shells with developable middle surfaces is a considerable point of engineering task, and it seems to be rather reasonable to obtain the simple formula for such analysis.

It is shown in the paper that the difference between results of displacements which are calculated by standard methods of resistance of materials and shell theory achieves 10 per cent. Since geometrically nonlinear task usually occurs in manufacturing process, the analysis is 
worth to be conducted with precise method of structural mechanics and shell theory.

As a future research topic, the suggested calculations can be improved by taking into account the displacements along the line $\mathrm{x}$, as well as the comparison with the results which can be obtained by numerical methods. The two presented tasks can also be used as test examples for numerical methods.

\section{References}

1. Ogibalov P.M., Koltunov M.A., Shells and Plates, Moscow Univ., 695pp. (1969).

2. Karmishin A.V., Lyaskovets V.A., Myachenkov V.I., Frolov A.N., Statics and dynamics of thin-wall shelltype structures, Moscow, Mashinoctroenie, $376 \mathrm{pp}$. (1975).

3. Valishvili N.V., Methods of analyzing shells of revolution on a digital computer, Mashinostroenie, 279pp. (1976).

4. Timoshenko S.P., Woinowsky-Krieger S. Theory of Plates and Shells, New York, McGrawHill, 595pp (1959).

5. Krivoshapko S.N., Parabolic bending of thin elastic plane or developable half-finished products into developable shell, Structural Mechanics of Engineering Constructions and Buildings, Vol. 12, P. 12-19 (2003).

6. Krivoshapko S.N., Gbaguidi G.L.A., Developable shell products made by parabolic bending of thin metal slabs, Journal of the Ghana Institution of Engineers, Vol. 6\&7, № 1, p. 51-56 (2009).

7. Elenitsky E.Ya., Boundary value problem for the flexible axially loaded compound shells of revolution and beams systems, Vestnik of Samara State Techn. Univ. (Techn. Scien. Series), 4 (29), pp. 122-130, (2012).

8. Krivoshapko S.N., Structural Mechanics: theory and practice, 2 edit., Moscow, Urait, 392 pp. (2014).

9. Krivoshapko S.N., Ivanov V.N., Encyclopedia of Analytical Surfaces, Springer International Publishing Switzerland, 752 pp. (2015).

10. Haeberli P., Modeling and fabrication of objects represented as developable surfaces, US Patent 6493603, USA (2002).

11. Rynkovskaya M.I., Analytical Methods of Analysis of Right and Open Helicoids, ASEE 2009 Conference: Engineering in the New Global Economy, USA, (2009).

12. Liua Y.-J., Tangb K., Gongc W.-Y., Wuc T.-R., Industrial design using interpolatory discrete developable surfaces, Computer-Aided Design, Vol. 43, Iss. 9, p. 1089-1098 (2011).

13. Krivoshapko S.N., Geometry of Ruled Surfaces with Edge of Regression and Linear Theory of Analysis of Developable Shells, Monograph, Izd-vo RUDN, 357pp. (2009).
14. Krivoshapko S.N., Static analysis of shells with developable middle surfaces, Appl. Mech. Rev., Vol. 51, №12, Part 1, pp. 731-746 (1998).

15. Redont P., Representation and deformation of developable surfaces, Computer Aided Geometric Design, Vol. 21 (1), p. 13-20 (1989).

16. Oetter R., Barry C.D., Duffty B., Welter J., Block Construction of Small Ships and Boats Through Use of Developable Panels, Journal of Ship Production, Vol. 18, №2, p. 65-72 (2002).

17. Steel-Chalfant J., Analysis and design of developable surfaces for shipbuilding, Master's thesis (1997).

18. Gotman A.S., Use of Developable Surfaces for Designing Well-Stream Shapes, Oceanic Engineering International, Vol. 9, NUMB 2, p. 81-96 (2005).

19. Koschitz D., Demaine E.D., Demaine M.L., Curved Crease Origami, Abstracts from Advances in Architectural Geometry (AAG 2008), p. 29-32 (2008).

20. Tevfik A., Ahmet K., Ergun A., Developable sculptural forms of Ilman Koman, Tarquin Publications, London (2006).

21. Solomon J., Vouga E., Wardetzky M., Grinspun E., Flexible Developable Surfaces. Computer Graphics Forum, Vol. 31, Iss. 5, p. 1567-1576 (2015).

22. Yoon J.S., Ryu C., Lee J.H., Developable polynomial surface approximation to smooth surfaces for fabrication parameters of a large curved shell plate by Differential Evolution, ComputerAided Design, V. 40, Iss. 9, p. 905-915 (2008).

23. Xia M., Yan Q., Zuo D., Xie J., An investigation on multistage bending of blank sheet into cylindrical tube by experiment and numerical simulation, Int. J. of Adv. Manuf. Tech., Vol. 53, Iss. 1-4, p. 145-155 (2011).

24. Kilian M., Flory S., Chen Z., Mitra N.J., Sheffer A., Pottman H., Curved Folding, ACM Transactions on Graphics (TOG), Vol. 27, Iss. 3, Article № 75 (2008).

25. Rose K., Sheffer A., Wither J., Cani M.-P., Thibert B., Developable Surfaces from Arbitrary Sketched Boundaries, SGP '07 Proceedings of the fifth Eurographics symposium on Geometry processing. P. 163-172 (2007).

26. Dias M. A., Dudte L. H., Mahadevan L., Santangelo C. D., Geometric Mechanics of Curved Crease Origami, Physical Review Letters 109, 114301 (2010).

27. Jung A., Hahmann S., Rohmer D., Begault A., Boissieux L., Cani M.-P., Sketching Folds: Developable Surfaces from Non-Planar Silhouettes, ACM Transactions on Graphics (TOG), Vol. 34, Iss. 5, Article No. 155 (2015).

28. M. Rynkovskaya. Plastic deformations in the shells with developable middle surfaces while bending, ICONTES 2016 (to be published). 